\title{
Work-family conflict, job satisfaction and spousal support: An exploratory study of nurses' experience
}

\author{
CJ Patel, MA-Counselling Psychology \\ Lecturer, School of Psychology, UKZN
}

A Beekhan, B Soc Sc (Hons)

Masters student, School of Psychology, UKZN

Z Paruk, MA-Clinical Psychology

Lecturer, School of Psychology, UKZN

S Ramgoon, MA-Counselling Psychology

Lecturer, School of Psychology, UKZN

Key Words:

Work-family conflict; job satisfaction; spousal support; nurses.
Correspondence address:

Cynthia J Patel

School of Pshychology

Howard College Campus

King George V Ave

Durban

4041

Tel : (031) 260-7619

Fax : (031) 260-2618

E-mail : patelc@ukzn.ac.za

\section{Abstract: Curationis 31(1): 38-44}

In recognising the highly stressful nature of the nursing profession, the added burden of hospital staff shortages, and patient overload, the present study explored the impact of work on family functioning, its relationship to job satisfaction and the role of spousal support in a group of 80 female nurses working in a government hospital. Using a descriptive, correlational design, the relationships among job satisfaction, work-family conflict (WFC) and spousal/partner support were explored. The hypotheses that job satisfaction and WFC would be negatively correlated, that job satisfaction and spousal support would be positively correlated, and that WFC and spousal support would be negatively correlated, were tested using correlation techniques. All hypotheses were confirmed. The role of spousal support in the relationship between job satisfaction and work -family conflict was highlighted.

\section{Introduction and background}

The growing shortage of hospital nurses appears to be a worldwide problem (Aiken, Clarke, Sloane, Sochalski \& Silber, 2002:1987; Rutter, 2001:1171; Simon, Kümmerling \& Hasselhorn, 2004:384). Factors linked to this situation include the high turnover rate, with nurses either leaving the profession or migrating to other countries (Aiken, Buchan, Sochalski, Nichols \& Powell, 2004:69; Coombes, 2005:923; Padarath, Chamberlain, McCoy, Ntuli, Rowson, \& Loewenson, 2003:16), and the decrease in the number of individuals offering themselves for training as nurses (DENOSA 2001, cited in Ehlers, Oosthuizen, Bezuidenhout, Monareng \& Jooste, 2003:25).

Lu, While and Barriball (2005:215) cite research which shows that low job satisfaction is most commonly linked to nurses' turnover. Work overload, long hours of work, shift work, staff shortages, intensity of work, undervalued work and poor salaries have been identified as reasons for dissatisfaction among nurses. According to Rutter (2001:1172) a WHO survey shows that developed nations are increasingly looking abroad to address their nursing shortages. Rutter (2001:1171) points out that this only 
serves to exacerbate the shortage in developing countries. South Africa is one of the targeted countries from which nurses are being recruited (Aiken et al., 2004:71 ). Ehlers et al. (2003:29) report that nurses can earn up to ten times more overseas than they do in South Africa if one includes offers of tax free salaries, bonuses, free housing, medical aid and airfares. In addition, the low growth rate of qualified nurses has meant that the country's health services have not kept pace with population growth and are not adequately resourced to cope with the additional demands of the HIV/AIDS epidemic (Subedar, 2005:100). Those nurses, who are not in a position to migrate or choose not to, are left to deal with the work overload, undesirable nurse-to-patient ratios and poor salaries. Other problems that Padarath et al. (2003:17) highlight include inadequate medical supplies, management and bureaucratic inefficiencies and lack of organizational support. In short, these are working conditions that are likely to impact on the quality of care that nurses are able to deliver and their levels of satisfaction with their jobs. Levert, Lucas \& Ortlepp (2000: 36) report research which supports the view that sources of stress which are inherent in the nursing role are common regardless of ward or nursing specialty. The relationship between work stress and physical and mental health has been well established (Levert et al., 2000:37). In particular, the link between burnout and job satisfaction among nurses (Bacharach, Bamberger \& Conley, 1991:50; Renzi, Tabolli, Ianni, Di Petro \& Puddu, 2005:154-155) has been demonstrated. Both Sheward, Hunt, Hagen, Macleod \& Ball (2005:57) and Aiken et al. (2002:1990) found that the growing patient-to-nurse ratio was one of the main factors linked to risks of emotional exhaustion and job dissatisfaction. Forty three percent of the nurses in the latter study, who reported high burnout and job dissatisfaction, expressed the intention to leave their jobs in the next 12 months. Rode (2004:1205) observes that after more than three decades of investigation, researchers have concluded that job satisfaction influences or 'spills over' into life satisfaction, which encompasses satisfaction with family, health and work

\section{Job satisfaction, work-family conflict and spousal support}

Lu, While and Barriball (2005:212) describe job satisfaction as a "global feeling about the job" or as a combination of inter-related attitudes about different aspects of the job. Their review of the literature on job satisfaction measures used with nurses showed that the sources of satisfaction are somewhat similar: physical working environment, inter-relationships with colleagues, pay, promotion prospects, job security, acknowledgement and responsibility. If nurses have negative experiences with these aspects of the job, then not only will it impact on their well-being, it also has the potential to spill over and affect the family life of these health workers. Bacharach et al. (1991:39) observe that although the relationship between role stress and job satisfaction has been comprehensively researched, these attempts do not show how stress experienced in the work and home realms 'spill over' or impact each other. Several studies have demonstrated a relationship between work and family conflict and job satisfaction (Frye \& Breaugh, 2004:211; Grandey, Cordeiro \& Crouter, 2005:316), while others have failed to do so (Eagle, Icenogle, Maes \& Miles, 1998:701). Luk and Shaffer (2005:491) argue that support resources can buffer the impact of stressors on WFC. In this regard, while spousal support has been examined in relation to marital satisfaction (Aycan \& Eskin, 2005:464; Burley,1995:491-493; Purdom, Lucas \& Miller, 2006:6-8), to WFC (Aycan \& Eskin, 2005:465; Cinamon \& Rich, 2002:214) and to job satisfaction (Phillips-Miller, Campbell \& Morrison 2000:16-17), it has not been examined in the context of both job satisfaction and WFC. Specifically, the link between job satisfaction, spousal support and WFC among nurses has not been adequately explored.

\section{Nursing}

Nursing is a traditionally female dominated occupation, strongly associated with cultural expectations of women as nurturers. According to gender role theory, society expects women to display this role in the private sphere (home) and, in the case of nurses, extend it to the public (work) role. For female nurses this presents a particular challenge in which, ironically, the same societal demands (as carer and nurturer) are expected in both the family and work realms. The work-family debate becomes even more relevant in a predominantly female profession in a society where care is highly gendered and generally undervalued. Hockey (1997:294) notes that the Department of Health (U.K) (1994) figures show that two-thirds of women employed as nurses are on parttime contracts while just over 10 percent of male nurses are employed part-time. This suggests that women curb their work hours because of domestic demands. Corley and Mauksch's (1988:142) interviews with nurses revealed that even though they were not aware of it, their values of caring and commitment allowed them to be exploited in the work setting When these problems are pointed out by nurses, their complaints are treated as a failure to demonstrate what is regarded as a natural gift - caring. They are devalued through the idea that caring is a natural asset. Given that expectations are grounded in societal beliefs about women as nurturers, it is surprising to note that research on nurses' experiences of WFC is so limited.

\section{Related research}

Bullock and Waugh (2004:771-781) conducted focus groups with diverse groups of female nurses to examine their differential experiences of paid and unpaid care-giving with special emphasis on the pressure to adhere to stereotypical expectations of caring both on and off the clock. They also explored opportunities and difficulties with advancement in a "woman friendly field" The finding that women, in general, were satisfied with the ways in which they managed to balance work and family responsibilities, may have been a function of the fact that half the sample were in higher status positions which do not involve the more undesirable tasks involved in paid care-giving. These participants actually chose positions where work and family conflicts could be avoided. They did, however, comment on the tendency to provide empathy and care at work because these were central expectations of employment, but found themselves having to enforce boundaries at home as a result of them having 'less to give'. The significance of these findings with regard to tension between work and home was evident in the researchers concluding that one of the themes emerging from their findings was the 'cost' of caring and emotional labour associated with their jobs on family life.

\section{Problem statement}

Given the highly stressful nature of the nursing profession, the added burden of staff shortages, long hours of work, 
patient overload and general dissatisfaction with salaries, the purpose of the present study was to explore the impact of work on family functioning, its relationship to job satisfaction and the role of spousal support in a small group of nurses.

\section{Conceptual and operational definitions \\ Work-family conflict (WFC)}

According to role strain theory, the demands experienced in one role (for example, work) take time and energy away from demands experienced in another role (for example, family). Greenhaus and Beutell (1985:77) refer to this type of role conflict, in which "opposing pressures arise from participation in different roles" as inter-role conflict. Although the nurses in Burke and Greenglass's (2001:592) study indicated higher workto-family conflict (WFC) than family-towork conflict (FWC), both types of conflict were linked with higher levels of burnout. Frone, Russell and Cooper (1992:72) found that while work stressors were positively linked with WFC, family stressors were linked to FWC. Burke and Greenglass (2001:585) also make the point that research has consistently demonstrated the link between work stressors and family functioning.

Several measures of WFC used in past research have been found to be problematic and according to Greenhaus and Beutell (1985:83-86), may have hindered past research. The use of one or two-item scales raises concerns about the psychometric soundness of these instruments. According to Nunnally (1978:243) and Oppenheim (1992:147) the reliability of a scale improves with a larger set of items.

Several studies have used global or general measures of WFC and do not specify direction of conflict (Stephens \& Sommer, 1996:476). The review by Kossek and Ozeki (1998:140) shows that workfamily measures that indicate the direction of role conflict perform better than measures combining both directions. In response to these criticisms Stephens and Sommer (1996:481) developed a methodologically sound measure of work to family conflict which includes time, strain, and behaviour based dimensions of work to family conflict, all of which fit with the theoretical structure described by Greenhaus and Beutell (1985:78). Of relevance to the present study was the fact that just under half of their sample was made up of hospital staff.

\section{Job Satisfaction}

While several studies have used single items to measure level of job satisfaction, Herzberg's (1966) theory of job satisfaction (cited in Lu et al., 2005:212) which loosely translates into two categories of needs: intrinsic (motivators) and extrinsic (related to the work environment), has a stronger conceptual base. Job satisfaction, according to Warr, Cook and Wall (1979:133) refers to the extent to which a person is satisfied with the intrinsic (the job itself) and extrinsic (work conditions) aspects of the job. Kacel, Miller and Norris (2005:28) examined intrinsic and extrinsic aspects of the job using the Misener Nurse Practitioner Job Satisfaction Scale. Since the scale includes a number of issues unique to nurse practitioners' work situations it was not considered suitable for the present study. The 15-item scale used by Warr et al. (1979:145-146), although not previously used with nurses, covers the main sources of stress (both intrinsic and extrinsic factors): work conditions, salary recognition, promotion opportunities, management, staff relations and work hours.

\section{Spousal support}

Although some studies identify spousal support as a potential mediator variable in the relationship between perceived stressors and role strain, well-being and marital quality, the results have not been conclusive. In the present study, the variable of spousal support is defined as direct and indirect encouragement received from a spouse/partner or significant other. It is included in order to explore its relationship with WFC and job satisfaction.

\section{Hypotheses}

1. Job satisfaction is negatively correlated with WFC.

2. Spousal support is negatively correlated with WFC.

3. Spousal support is positively correlated with job satisfaction.

\section{Methodology}

\section{Research design}

In order to test the hypotheses of relationships between job satisfaction, spousal support and WFC, a correlational design was used. In this type of design, “...descriptions are constructed by means of the relationships between variables..." (Mouton \& Marais, 1990:44). While this design is useful in instances where experimental designs are not appropriate and where the intention is to explore theoretical or conceptual associations between variables, it has certain shortcomings. Huysamen (1998:106-108) describes the 'third variable problem' as a factor that influences the internal validity of this type of non-experimental research. This refers to the possibility that a high correlation between two variables (for example, $X$ and $Y$ ) may be explained by a third variable $(Z)$ which has high correlations with both $\mathrm{X}$ and $\mathrm{Y}$. The relationship between $X$ and $Y$ is said to be spurious because of their separate relationships with $\mathbf{Z}$.

The reliability estimates reported by other researchers for the scales used are described in the 'Instruments' section.

\section{Participants}

The mean age of the sample of nurses who indicated their age $(n=74)$ was 36.27 years, with ages ranging from 22 to 62 years.

Over fifty percent of the female sample was married or had a live-in partner, while $76.3 \%$ had children. The average number of years the nurses were employed at the hospital was 5.22 years.

\section{Instruments}

In addition to a short demographic questionnaire, three scales were administered to the sample of nurses: The WFC scale (Stephen \& Sommers 1996:481), a job satisfaction scale (Warr et al.,1979:145-146) and a 1-item spousal social support measure used by Burley (1995:488).

\section{WFC}

The instrument developed by Stephens and Sommer (1996: 481) consists of 14 items, measuring time, strain and behaviour-based dimensions of WFC. The internal consistency measures reported by the authors for the three subscales were $0.74,0.84$ and 0.72 respectively. A five-point Likert scale, ranging from "Strongly disagree" (1) to "Strongly agree" (5), was used.

\section{Job Satisfaction}

Warr et al. (1979:145-146) used 15 items to measure intrinsic ( 7 items) and extrinsic (8 items) job satisfaction and a single item to assess overall job satisfaction. The Likert-type response format ranged from "Extremely Dissatisfied" (1) to "Extremely Satisfied" (7). In their studies, the reported internal consistency values ranged from 
0.79 to 0.85 for intrinsic satisfaction, 0.74 to 0.78 for extrinsic satisfaction, and 0.85 to 0.88 for total job satisfaction.

Spousal social support

Burley's (1995: 488) measure of spousal support, used with professionals in psychology, was adapted slightly for the present study: It was changed from "How much social support do you receive from your spousel significant other for your present job in psychology?" to "How much social support do you receive from your spousel significant other for your present job?" The sample was asked to respond to the question on a 4-point Likert scale, ranging from a great deal (4) to none (1). For the purpose of this study the term spousal support is used to refer to support of the spouse/ significant other.

\section{Procedure}

Ethical clearance to conduct the study was obtained from both the hospital authorities and the Higher Degrees Committee of the
Faculty of Humanities, Development and Social Science at the University of KwaZulu-Natal. Although the hospital has approximately 700 nursing staff, just over 80 volunteered to participate in the study. A copy of the cover letter, an informed consent form and a set of the measurement scales were left with each volunteer to complete during the lunch break. The completed questionnaires, eighty in total, were collected at the end of the week.

\section{Results}

Descriptive statistics, t-tests and

\section{Table 1: Means and standard deviations of the WFC scale, Job Satisfaction scale, spousal support for total sample $(n=80)$}

\begin{tabular}{lllc}
\hline & Mean & SD & Cronbach's alpha \\
WFC (Total) & 50.35 & 10.12 & 0.88 \\
Time-based conflict & 14.34 & -3.55 & 0.74 \\
Strain based conflict & 15.04 & 3.75 & 0.84 \\
Behaviour-based conflict & 20.54 & 4.45 & 0.72 \\
Job Satisfaction (Total) & 52.29 & 17.08 & 0.89 \\
Intrinsic job satisfaction & 21.91 & 8.05 & 0.83 \\
Extrinsic job satisfaction & 26.63 & 7.97 & 0.75 \\
Overall job satisfaction (1 item) & 3.72 & 1.75 & \\
Spousal support (1 item) $(\mathrm{n}=34)$ & 2.43 & 1.12 & \\
\hline
\end{tabular}

Table 2: Inter-correlations between age, WFC, job satisfaction, spousal support

\begin{tabular}{|c|c|c|c|c|c|c|c|c|c|}
\hline & (2) & (3) & (4) & (5) & (6) & (7) & (8) & (9) & (10) \\
\hline (1) Age & $0.30^{*}$ & $0.37^{* *}$ & $0.28 *$ & 0.23 & -0.17 & -0.15 & $-0.29 *$ & -0.05 & -0.01 \\
\hline (2) JS Total & & $0.97 * *$ & $0.96^{* *}$ & $0.81^{* *}$ & $-0.64 * *$ & $-0.51 * *$ & $-0.55^{* *}$ & $-0.57 * *$ & $0.46^{* *}$ \\
\hline (3) Internal JS & & & $0.87 * *$ & $0.76^{* *}$ & $-0.61^{* *}$ & $-0.48 * *$ & $-0.56 * *$ & $-0.50 * *$ & $0.51^{* *}$ \\
\hline (4) External JS & & & & $0.73 * *$ & $-0.60^{* *}$ & $-0.41 * *$ & $-0.53 * *$ & $-0.55^{*}$ & $0.36^{*}$ \\
\hline (5) JS Overall & & & & & $-0.48^{* *}$ & $-0.35^{* *}$ & $-0.42^{* *}$ & $-0.49 * *$ & $0.40^{*}$ \\
\hline (6) WFC Total & & & & & & $0.84 * *$ & $0.86^{* *}$ & $0.85^{* *}$ & $-0.36^{*}$ \\
\hline (7) Time WFC & & & & & & & $0.65^{* *}$ & $0.56^{* *}$ & $-0.38 *$ \\
\hline (8) Strain WFC & & & & & & & & $0.57 * *$ & -0.23 \\
\hline (9) Behaviour WFC & & & & & & & & & $-0.34^{*}$ \\
\hline (10) Spousal support & & & & & & & & & \\
\hline
\end{tabular}

JS Total - Job Satisfaction Total

${ }^{*} \mathrm{p}<0.05{ }^{* *} \mathrm{p}<0.01$

Internal JS - Internal Job Satisfaction

External JS - External Job Satisfaction

JS Overall - Overall Job Satisfaction

WFC Total - WFC Total

Time WFC-Time-based WFC

Strain WFC - Strain-based WFC

Behaviour WFC - Behaviour-based WFC 


\section{Table 3: Means, standard deviations and t-tests on WFC and job satisfaction by level of social support}

\begin{tabular}{|c|c|c|c|c|c|c|}
\hline & \multicolumn{5}{|c|}{ Spousal Support } & \multirow{3}{*}{$\mathrm{t}$} \\
\hline & & Lo & & $\mathrm{Hi}$ & & \\
\hline & & $\begin{array}{l}\text { Mean } \\
\quad(\mathrm{n}=\end{array}$ & SD & $\begin{array}{l}\text { Mean } \\
(n=\end{array}$ & & \\
\hline \multirow{2}{*}{\multicolumn{2}{|c|}{ WFC (Total) }} & 54.89 & 10.20 & 47.44 & 9.60 & $2.19 *$ \\
\hline & & \multicolumn{2}{|c|}{$(n=19)$} & \multicolumn{2}{|c|}{$(n=15)$} & \\
\hline Job Satisfaction & (Total) & 43.95 & 13.15 & 56.27 & 17.16 & $-2.29 *$ \\
\hline
\end{tabular}

${ }^{*} \mathrm{p}<0.05$

Pearson correlations were conducted using the Statistical Package for the Social Sciences (SPSS) Version 13.

As can be seen from Table 1, Cronbach' $s$ alpha for both the subscales and total scores of both instruments revealed moderate to strong inter-item consistency.

Analysis of the relationships between WFC, job satisfaction and spousal support as reflected in Table 2 revealed significant relationships in the expected direction. In general, the following (significant) patterns emerged:

The higher the job satisfaction the lower the WFC.

The higher the spousal support the lower the WFC.

The higher the spousal support the higher the job satisfaction.

Age was positively correlated with job satisfaction and negatively correlated with strain-based WFC.

Further support for the role of spousal support in job satisfaction and WFC is provided in Table 3. The responses to the spousal support item were recoded so that those indicating 'very little' and 'none' were categorized 'low spousal support' and those indicating ' $\mathrm{A}$ fair amount' and 'A great deal' were categorized 'high spousal support'. Independent samples $t$-tests revealed significant differences with the high spousal support' group showing higher job satisfaction and lower WFC than the 'low spousal support' group.

\section{Discussion}

Over the years research has identified job satisfaction as a significant predictor of job turnover (Porter \& Steers, 1973:151; Lu et al., 2005:215; research cited by Balmforth \& Gardner, 2006:70). The low levels of job satisfaction found in the present sample of nurses therefore, have definite implications for the already stretched resources of the country's health care services. The job satisfaction scores $($ Mean $=51.38$ ) were found to be significantly lower $(t=4.69 ; \mathrm{p}<0.001)$ than Warr et al's. (1979:135) original sample of manual workers $($ Mean $=69.86$ ) and a sample of university graduates (Mean = 74.61). In the case of manual workers, Argyle (1990:237-238) describes research which shows low job satisfaction in this group citing low autonomy, unchallenging work and the limited skill required as causal factors. With nurses however, the work conditions and the range of stressors inherent in the nursing profession are probably directly responsible for their low levels of job satisfaction.

In keeping with the hypothesis and with previous research findings (Kossek \& Ozeki, 1998:141-144; Frye \& Breaugh, 2004:214; Grandey et al., 2005:315), JS correlated negatively with all three dimensions of WFC: work-based, strainbased and behaviour-based conflict. The findings indicate that nurses who are more satisfied with their jobs appear to be less likely to allow work to encroach on their family lives. The research literature, however, has tended to highlight FWC over WFC as having a greater association with job satisfaction (Kossek \& Ozeki, 1998: 140). Balmforth and Gardner (2006:73), using quantitative measures, failed to find a significant relationship between JS and either WFC or FWC among their sample of employees ( $76 \%$ female) of a human resource consultancy. The qualitative component of the study, however, identified WFC as an important theme. The WFC experiences articulated by the respondents showed how the demands of work impacted on WFC. The authors make the points that greater satisfaction with work appears to depend on a supportive work environment and that organisations need to be sensitive to ways in which work demands influence family life.

While the significance of organizational support has been well documented (Aycan \& Eskin, 2005:454), the potential support that families, more specifically spouses/partners can and do offer has not been adequately addressed. The present study, albeit using a single item measure, shows definite predictive potential of spousal support in job satisfaction and WFC. In addition to the correlational analysis, t-tests corroborated these findings, with higher job satisfaction scores and lower WFC in the group receiving greater spousal support. With more men beginning to share family responsibilities, the level of support experienced by their partners is likely to be higher than that of women whose partners endorse traditional gender roles. The women in more egalitarian relationships are probably better able to deal with work stressors and experience less WFC. This is likely to free them emotionally to derive intrinsic satisfaction from their work.

Although an examination of the relationship between age and the main variables was not one of the aims of the study, the finding of a significant positive relationship between age and job satisfaction, is worthy of mention. Argyle (1990:244) cites research that indicates that older people tend to be more satisfied with their jobs, even when the rewards associated with higher status are held constant. The authors of these studies suggest that older people learn to adjust to their work situations. It is also possible that when work is an integral part of a person's identity, it will have greater intrinsic meaning and contribute to greater job satisfaction for the older person.

In general our hypotheses were confirmed: job satisfaction was related negatively to WFC and positively to spousal support, and WFC was negatively related to spousal support.

The implication of our findings is that the impact of spousal support as a possible variable in the job satisfaction and WFC relationship needs to be recognized and explored in interventions 
aimed at reducing stress amongst nurses. However, in recognizing the limitation of using a single item as a measure of spousal support in this study, we recommend that future research utilize a more psychometrically sophisticated instrument. An additional limitation is our failure to obtain employment status of respondents' partners, given that dual career relationships are increasingly being perceived as having implications for spousal support and WFC.

\section{References}

AIKEN, LH; CLARKE, SP; SLOANE, DM; SOCHALSKI, J \& SILBER, JH

2002: Hospital nurse staffing and patient mortality, nurse burnout, and job dissatisfaction. JAMA, 288(16):19871993.

AIKEN,LH; BUCHAN,J; SOCHALSKI, J; NICHOLS, B \& POWELL, M 2004:

Trends in international nurse migration. Health Affairs, 23(3):69-77.

ARGYLE, M 1990: The social psychology of work. London: Penguin Books.

AYCAN, Z \& ESKIN, M 2005: Relative contributions of childcare, spousal support, and organizational support in reducing work-family conflict for men and women: The case of Turkey. Sex Roles, 53(7/8):453-471.

BACHARACH,SB; BAMBERGER, P \& CONLEY, S 1991: Work-home conflict among nurses and engineers: Mediating the impact of role stress on burnout and satisfaction at work. Journal of Organizational Behavior, 12(1):39-53.

BALMFORTH, $K$ \& GARDNER, D 2006: Conflict and facilitation between work and family: Realizing the outcomes for organizations. New Zealand Journal of Psychology, 35(2):69-76.

BULLOCK, HE \& WAUGH, IM 2004: Caregiving around the clock: How women in nursing manage career and family demands. Journal of Social Issues, 60(4):767-786.

BURKE, RJ \& GREENGLASS, ER 2001: Hospital restructuring, workfamily conflict and psychological burnout among nursing staff. Psychology and Health, 16:583-594.

BURLEY, KA 1995: Family variables as mediators of the relationship between work-family conflict and marital adjustment among dual-career men and women. The Journal of Social Psychology, 135(4):483-497.

CINAMON, RG \& RICH, Y 2002: Profiles of attribution of importance to life-roles and their implications for the work-family conflict. Journal of Counseling Psychology, 49(2):212-220.

COOMBES, R 2005: Developed world is robbing African countries of health staff. British Medical Journal, 330(7497):923.

\section{CORLEY,MC \& MAUKSCH,HO 1988:}

Registered nurses, gender and commitment. (In Statham, A; Miller, EM \& Mauksch, HO, eds. 1988: The worth of women's work Albany: State University of New York Press, p.135-149)

EAGLE, BW; ICENOGLE, ML; MAES, JD \& MILES, EW 1998: The importance of employee demographic profiles for understanding experiences of workfamily interrole conflicts. The Journal of Social Psychology, 138(6):690-709.

EHLERS, VJ; OOSTHUIZEN, MJ; BEZUIDENHOUT,MC; MONARENG, LV \& JOOSTE, K 2003: Post-basic nursing students' perceptions of the emigration of nurses from the Republic of South Africa. Health SA Gesondheid, 8(4):24-37.

FRONE, MR; RUSSELL, M; \& COOPER, ML 1992: Antecedents and outcomes of work-family conflict: Testing a model of the work-family interface. Journal of Applied Psychology, 77(1):6578.

FRYE, NK \& BREAUGH, JA 2004: Family-friendly policies, supervisor support, work-family conflict, family-work conflict, and satisfaction: A test of a conceptual model. Journal of Business and Psychology, 19(2):197-220.

GRANDEY, AA; CORDEIRO, BL \& CROUTER, AC 2005: A longitudinal and multi-source test of the work-family conflict and job satisfaction relationship. Journal of Occupational and Organizational Psychology, 78:305-323.

GREENHAUS, JH \& BEUTELL, NJ 1985: Sources of conflict between work and family roles. Academy of

\section{Management Review, 10:76-88.}

HOCKEY, J 1997: Women and health. (In Robinson, V \& Richardson, D, eds. 1997: Introducing Women's Studies. London: Macmillan, p. 282-302)

HUYSAMEN, GK 1998: Methodology for the social and behavioural sciences. Johannesburg: Thomson Publishing.

KACEL, B; MILLER, M \& NORRIS, D 2005: Measurement of nurse practitioner job satisfaction in a midwestern state. Journal of the American Academy of Nurse Practitioners, 17(1):27-32.

KOSSEK, EE \& OZEKI, C 1998: Workfamily conflict, policies, and the job-life satisfaction relationship: A review and directions for organizational behaviorhuman resources research. Journal of Applied Psychology, 83(2):139-149.

LEVERT, T; LUCAS, M \& ORTLEPP, K 2000: Burnout in psychiatric nurses: Contributions of the work environment and a sense of coherence. South African Journal of Psychology, 30(2):36-43.

LU,H; WHILE,AE \& BARRIBALL, KL 2005: Job satisfaction among nurses: a literature review. International Journal of Nursing Studies, 42:21 1-227.

LUK, DM \& SHAFFER, MA 2005: Work and family domain stressors and support: Within- and crosș-domain influences on work-family conflict. Journal of Occupational and Organisational Psychology, 78:489-508.

MOUTON, J \& MARAIS, HC 1990: Basic concepts in the methodology of the social sciences. Pretoria: HSRC Press.

NUNNALLY, JC 1978: Psychometric Theory. New York: McGraw-Hill.

OPPENHEIM, AN 1992: Questionnaire design, interviewing and attitude measurement. London: Pinter Publishers.

PADARATH, A; CHAMBERLAIN, C; MCCOY,D; NTULI,A; ROWSON,M \& LOEWENSON, R 2003: Health personnel in Southern Africa: Confronting maldistribution and brain drain. Equinet discussion paper number 3. Retrieved August 4, 2006 from the World Wide Web:

http://www.equinetafrica.org/bibl/docs/ healthpersonnel.pdf 
PHILLIPS-MILLER, DI : CAMPBELL, NJ \& MORRISON, CR 2000: Work and family: Satisfaction, stress, and spousal support. Journal of Employment Counseling, 37:16-30.

PORTER, L \& STEERS, R 1973: Organizational, work, and personal factors in employee turnover and absenteeism. Psychological Bulletin, 80:151-176.

PURDOM, CL; LUCAS,JL \& MILLER, KS 2006: Couple type, parental status and the mediating impact of social support. North American Journal of Psychology, 8(1):1-12.

RENZI, C; TABOLLI, S; IANNI, A; DI PETRO, C \& PUDDU, P 2005: Burnout and job satisfaction comparing healthcare staff of a dermatological hospital and a general hospital. Journal of the European Academy of Dermatology and Venereology, 19:153157.

RODE, JC 2004: Job satisfaction and life satisfaction revisited: A longitudinal test of an integrated model. Human Relations, 57(9): 1205-1230.

RUTTER, T 2001: Job discontent fuels aggressive recruitment of nurses. Bulletin of the World Health Organisation, 79(12):1171-1172.

SHEWARD, L; HUNT, J; HAGEN, S; MACLEOD, M \& BALL, J 2005: The relationship between UK hospital nurse staffing and emotional exhaustion and job dissatisfaction. Journal of Nursing Management, 13:51-60.

SIMON, M; KÜMMERLING, A \& HASSELHORN, H-M 2004: Work-home conflict in the European nursing profession. International Journal of Occupational and Environmental Health, 10(4):384-391.

STEPHENS, GK \& SOMMER, SM 1996: The measurement of work to family conflict. Educational and Psychological Measurement, 56(3):475-486.

SUBEDAR, H 2005: The nursing profession: Production of nurses and proposed scope of practice. (In Ijumba, P \& Barron, P, eds. 2005: South African Health Review. Health Systems Trust. Retrieved August 4, 2006 from the World Wide Web: http://www.hst.org.zal uploads/files/sahr05 chapter7.pdf

WARR, P; COOK, J \& WALL, T 1979:

Scales for the measurement of some work attitudes and aspects of psychological well-being. Journal of Occupational Psychology, 52:129-148. 